\title{
Assessment of Alloxan-Induced Diabetic Rats as a Periodontal Disease Model Using a Selective Cyclooxygenase (COX)-2 Inhibitor
}

\author{
Yutaka Nakahara $^{1 \#^{*}}$, Kiyokazu Ozaki $^{1 \#}$, Tomoya Sano ${ }^{1}$, Yasushi Kodama ${ }^{2}$, and Tetsuro Matsuura ${ }^{1 *}$ \\ ${ }^{1}$ Department of Pathology, Faculty of Pharmaceutical Sciences, Setsunan University, 45-1 Nagaotoge-cho, Hirakata, Osaka 573-0101, \\ Japan \\ ${ }^{2}$ Laboratory of Clinicopathological Therapeutics, Faculty of Pharmaceutical Sciences, Hiroshima International University, 5-1-1 \\ Hirokoshingai, Kure, Hiroshima 737-0112, Japan
}

\begin{abstract}
Several recent studies have reported that alloxan-treated rats with long-term hyperglycemia can develop naturally occurring periodontal disease (PD). Our previous studies detected dental caries in the same model. Therefore, these two lesions of different etiologies are expected to occur concurrently. In this study, we evaluated the use of diabetic rats as a PD model by employing a selective COX-2 inhibitor reported to be effective against PD. Six-week-old female F344 rats were divided into 3 groups: intact rats (control), alloxan-induced diabetic rats fed a standard diet (AL) and alloxan-induced diabetic rats fed a diet containing $0.01 \%$ etodolac (AL+Et). The animals were euthanized at 26 weeks of age, and their oral tissues were examined histopathologically. Gingivitis, marginal periodontitis and alveolar bone resorption were markedly enhanced along with dental caries in the AL group compared with the control group. However, the COX-2 inhibitor had no effect on periodontal inflammation in the AL+Et group. In addition, in the AL group, periodontitis was notably nonexistent around the normal molars, and gingivitis was scarcely worse than that in the control group. In the diabetic rats, the progression of periodontal inflammation was closely correlated with the severity of adjacent dental caries, and marginal periodontitis was frequently continuous with apical periodontitis. In conclusion, an alloxan-induced diabetic rat is not a model of PD but of dental caries. It is probable that in this model, hyperglycemia may enable crown caries to progress to apical periodontitis, while the associated inflammation may rostrally expand to surrounding periodontal tissue. (DOI: 10.1293/tox.2013-0064; J Toxicol

Pathol 2014; 27: 123-129)
\end{abstract}

Key words: diabetes, alloxan, periodontitis, dental caries, cyclooxygenase (COX)-2 inhibitor

\section{Introduction}

Periodontal disease (PD) is the most common oral infection caused by periodontal pathogens and the main cause of tooth loss in adults. Gingivitis, marginal periodontitis and alveolar bone resorption are the pathognomonic lesions for PD. Diabetes and poor glycemic control are becoming important epidemiologic problems as risk factors for PD in humans ${ }^{1,2}$. Diabetic PD is even called the 6th complication of diabetes mellitus ${ }^{3}$. Nondiabetic rodents have been the usual animal models for human PD in experimental procedures such as oral or gingival inoculation with periodontal pathogens or lipopolysaccharides (LPSs) or placement of ligatures $^{4-6}$. Meanwhile, diabetic PD has been investigated

Received: 10 December 2013, Accepted: 6 February 2014 Published online in J-STAGE: 19 March 2014

*Corresponding authors: T Matsuura (e-mail: matsuura@pharm. setsunan.ac.jp), Y Nakahara (e-mail: richnchun@gmail.com)

${ }^{\#}$ These authors contributed equally to this study.

(C)2014 The Japanese Society of Toxicologic Pathology

This is an open-access article distributed under the terms of the Creative Commons Attribution Non-Commercial No Derivatives (by-ncnd) License $<$ http://creativecommons.org/licenses/by-nc-nd/3.0/> . in diabetic nonobese diabetic (NOD) mice with oral inoculation of PD-causing bacteria ${ }^{7}$, Zucker diabetic fatty rats and Goto-Kakizaki (GK) rats with ligatures around the mo$\operatorname{lars}^{8-10}$ and streptozotocin-induced diabetic rats with gingival inoculation of LPS $^{11}$. In recent studies, alloxan-treated rats with long-term hyperglycemia developed naturally occurring marginal periodontitis without the aforementioned experimental manipulations; therefore, they are suggested as a suitable model for spontaneous diabetic $\mathrm{PD}^{12,13}$.

Our previous studies have shown that dental caries is induced in longstanding diabetic rodents ${ }^{14,15}$ and that alloxan-induced severe hyperglycemia similarly leads to a rapid onset of progressive dental caries ${ }^{16}$. Therefore, both PD and dental caries, derived from completely different etiologies, are expected to occur concurrently in the teeth and adjacent periodontal tissues in the alloxan-induced diabetic rats. Our previous studies have also determined that carious inflammation spreads around the dental root through dental pulp and the apical foramen ${ }^{14-17}$. However, we could not eliminate the possibility that hyperglycemia may induce PD-derived inflammation in alloxan-induced diabetic rats ${ }^{12,13}$.

It has been suggested that the development of PD may be associated with prostaglandin (PG) production due to 
cyclooxygenase (COX) activity in both humans and animal models ${ }^{18-21}$. In clinical studies, nonsteroidal anti-inflammatory drugs (NSAIDs) have been shown to be effective in the treatment of $\mathrm{PD}^{22}$. In fact, selective COX-2 inhibitors have prevented the progression of periodontal inflammation and alveolar bone loss in the ligature-induced PD models ${ }^{23-25}$. Thus, if hyperglycemia actually induces diabetic PD in alloxan-treated rats, a selective COX-2 inhibitor would be expected to suppress PD-derived inflammation irrespective of the development of carious inflammation. The present study based on this hypothesis attempted to assess alloxan-treated rats with long-term hyperglycemia as potential diabetic PD models by using a selective COX-2 inhibitor.

\section{Materials and Methods}

\section{Animals and housing conditions}

Six-week-old female F344 rats were supplied by Japan SLC, Inc. (Hamamatsu, Japan). The animals were housed in stainless steel cages at a temperature of $20-26{ }^{\circ} \mathrm{C}$ with a relative humidity of $40-70 \%$, a $12 / 12 \mathrm{~h}$ light/dark cycle and ventilation with filtrated fresh air. To prevent infection, the cages were changed at least once a week. The rats were allowed free access to tap water and a powdered standard diet (Charles River Formula 1 [CRF-1]; Oriental Yeast Co., Ltd., Tokyo, Japan) or the same diet containing $0.01 \%$ etodolac (kindly provided by Nippon Shinyaku, Kyoto, Japan). Diets containing etodolac were prepared each week by mixing the powdered standard diet with a premix containing $1 \%$ etodolac at a ratio of 100:1. The etodolac dose was estimated on the basis of the dose of drug found not to induce gastric damage in 3- and 12-month oral toxicity studies in rats and the dose used to treat patients with osteoarthritis or rheumatoid arthritis ${ }^{26-28}$. The animals were handled according to the principles for all experimental procedures outlined in the Guide for the Care and Use of Laboratory Animals prepared by our institution (Setsunan University) and the Japanese Association for Laboratory Animal Science.

\section{Experimental design}

The experimental design is shown in Fig. 1. A total of 25 rats were randomly divided into 3 groups. Twenty rats, aged 7 weeks, were given a single dose ( $35 \mathrm{mg} / \mathrm{kg}$ body weight) of alloxan (Sigma-Aldrich Japan, Tokyo, Japan) via the tail vein. Alloxan, a pancreatic $\beta$-cell cytotoxic agent, was used to induce diabetes. The dose was selected according to the dose at which a rat survived for a long period of time after developing signs of diabetes and at which continuous glucosuria was induced ${ }^{16}$. After confirmation of hyperglycemia and glucosuria following alloxan administration, the 20 rats were divided into 2 groups. Ten rats were given a powdered standard diet (AL group), and the remaining 10 were given a powdered diet containing $0.01 \%$ etodolac (AL+Et group). The control group, 5 intact rats, was also given a powdered standard diet. Three rats died or were subjected to unscheduled sacrifice and were necropsied during the examination period. The remaining 22 rats were sacrificed at 26 weeks of

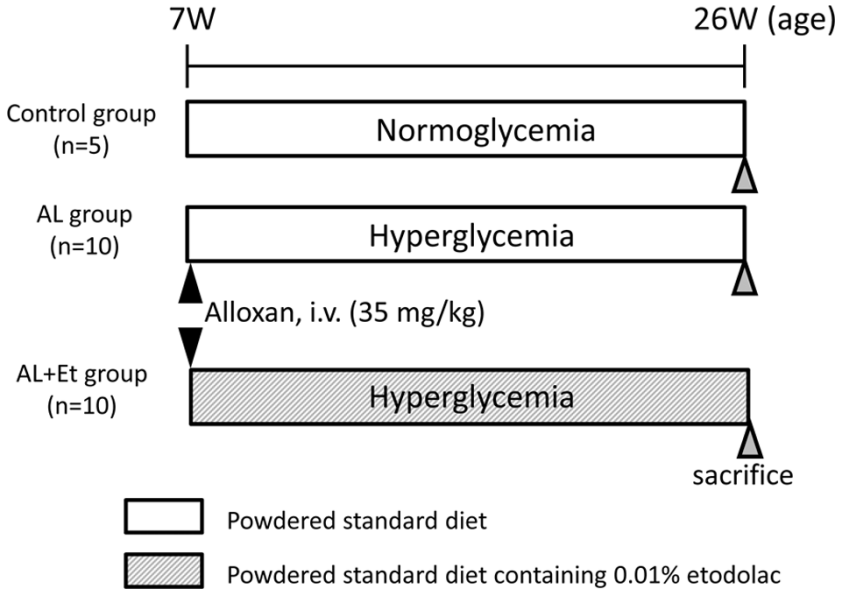

Fig. 1. Study design.

age for morphological examination.

\section{Clinical observation}

All rats were evaluated twice a day for morbidity and once a day for clinical signs of toxicity. The body weights of all animals were measured once a month.

\section{Glucosuria and glycemia monitoring}

Fresh urine samples were collected in metabolism cages. Glucose levels in the samples were measured semiquantitatively with urine test paper (Wako Pure Chemical Industries, Osaka, Japan) daily from day 1 to day 3 after dosing, once a week for 1 month after the first week and once a month thereafter. Blood glucose levels from tail vein samples were also measured semiquantitatively by using the glucose oxidase method (Glutest E; Sanwa Kagaku, Aichi, Japan) once a month starting in the 4th week after alloxan injection. The blood and urine samples were collected between 1:00 and 4:00 p.m. The severity of hyperglycemia was defined as follows: normal, $<200 \mathrm{mg} / \mathrm{dL}$; mild, $>200$ $\mathrm{mg} / \mathrm{dL}$; moderate, $>300 \mathrm{mg} / \mathrm{dL}$; or severe, $>400 \mathrm{mg} / \mathrm{dL}^{29}$. The severity of glucosuria was defined as follows: normal, $<100 \mathrm{mg} / \mathrm{dL}$; mild, $>100 \mathrm{mg} / \mathrm{dL}$; moderate, $>250 \mathrm{mg} / \mathrm{dL}$; or severe, $>500 \mathrm{mg} / \mathrm{dL}^{30}$.

\section{Grading for alveolar bone resorption and dental car- ies by soft $X$-ray examination}

The animals were anesthetized using intramuscular injection of ketamine hydrochloride $(40 \mathrm{mg} / \mathrm{kg}$ body weight; Ketalar, Sankyo, Tokyo, Japan) and xylazine hydrochloride (2.0 mg/kg body weight; Seractal, Bayer Japan, Tokyo, Japan). They were euthanized by exsanguination under deep anesthesia at the end of the observation period. Subsequently, the mandibles were removed and fixed in $10 \%$ neutralbuffered formalin ( $\mathrm{pH}$ 7.4) for $24 \mathrm{~h}$. After fixation, the occlusal, buccolingual and proximal surfaces of all molar teeth were intensively observed under a binocular stereoscope. Following macroscopic observation, a soft X-ray examination was performed. Soft X-ray images in the mesiodistal 
Table 1. Summary of the Grading Criteria for Histopathological Periodontal and Carious Lesions

\begin{tabular}{|c|c|}
\hline Findings (abbreviation) & Criteria \\
\hline \multicolumn{2}{|l|}{ Gingivitis (GV) } \\
\hline Mild (+) & Inflammatory cells infiltrated into the mucosal epithelium. \\
\hline Moderate $(++)$ & Inflammatory cells scattered throughout the gingival connective tissue with mucosal hyperplasia. \\
\hline \multicolumn{2}{|c|}{ Marginal periodontitis (MP) } \\
\hline Mild $(+)$ & Localized inflammatory cell infiltration in the periodontal ligament and/or resorption of the alveolar bone crest. \\
\hline Moderate $(++)$ & Inflammatory cell infiltration and alveolar bone resorption extending around the radicular area. \\
\hline \multicolumn{2}{|c|}{ Apical periodontitis (AP) } \\
\hline Mild (+) & Localized inflammatory cell infiltration and/or alveolar bone resorption in the apical aspect of the molar root. \\
\hline Moderate $(++)$ & Extensive inflammatory cell infiltration and alveolar bone resorption in the tissue around the molar root. \\
\hline \multicolumn{2}{|l|}{ Carious lesion $(\mathrm{C})$} \\
\hline Mild (+) & Dentin caries were localized in the occlusal surface of the dentin. \\
\hline Moderate $(++)$ & Dentin caries extended into dental pulp with pulpitis and pulp necrosis and/or decayed corona dentis. \\
\hline
\end{tabular}

plane were taken under the conditions of $35 \mathrm{kV}$ and $2 \mathrm{~mA}$ for $4 \mathrm{~min}$. The alveolar bone resorption and dental caries were graded according to a previously defined scoring system $^{17}$. The mean scores of each parameter were used to compare the severity of the lesions between the groups.

\section{Histopathological examination}

After the soft X-ray images had been obtained, histopathological examination was performed on the mandibles of all rats. The samples, which had previously undergone fixation with $10 \%$ neutral-buffered formalin, were decalcified in a 5\% solution of ethylenediaminetetraacetic acid tetrasodium salt (EDTA-4Na) for 2 weeks at $4^{\circ} \mathrm{C}$. After decalcification, the specimens were trimmed, dehydrated in a sequential ethanol series using an automated processor and embedded in paraffin wax. Serial $7-\mu \mathrm{m}$-thick sections through the centers of all molars on the mesiodistal plane were obtained, stained with hematoxylin and eosin and examined using light microscopy. The periodontal lesions (gingivitis, marginal periodontitis and apical periodontitis) and carious lesions were evaluated histopathologically. The grading criteria for the histopathological lesions are summarized in Table 1.

\section{Statistical analysis}

The Student's $t$-test was used for statistical analysis of the body weight data. The Wilcoxon rank-sum test was employed to compare the differences in the mean scores of alveolar bone resorption and dental caries found in the soft Xray examination. The chi-square test was used to determine the incidences of alveolar bone resorption and dental caries in the soft X-ray examination and the incidences of the histopathological lesions in each group of rats. The Pearson correlation was used to examine the associations between alveolar bone resorption and dental caries. A $p$ value of less than 0.05 was regarded as statistically significant.

\section{Results}

\section{General conditions}

During the study, 3 rats died or were subjected to unscheduled sacrifice because of moribund conditions. The causes of death or moribund conditions in these rats were either urinary tract infection or ketoacidosis resulting from severe diabetes. There were no changes in clinical observations in any surviving animals. The body weights of all alloxan-treated rats (AL and $\mathrm{AL}+\mathrm{Et}$ ) decreased within several days following injection of alloxan, and the average body weights of the AL and AL+Et groups approximately 26 weeks after injection were significantly lower than that of the control group (133.5 g, $131.8 \mathrm{~g}$ and $199.7 \mathrm{~g}$, respectively).

\section{Blood and urine glucose levels}

Severe hyperglycemia ( $>400 \mathrm{mg} / \mathrm{dL})$ and glucosuria $(>500 \mathrm{mg} / \mathrm{dL}$ ) began the day after injection of alloxan and continued through the last monitoring day in all rats in the alloxan-treated (AL and $\mathrm{AL}+\mathrm{Et}$ ) groups. In the control group, blood glucose levels ranged from 78 to $120 \mathrm{mg} / \mathrm{dL}$, and urine glucose levels were less than $100 \mathrm{mg} / \mathrm{dL}$ (Supplementary Table 1: on-line only).

\section{Changes in alveolar bone resorption in the soft X-ray examination}

In both alloxan-treated groups, alveolar bone resorption was clearly detected in the apical area adjacent to the carious molars (Fig. 2B, 2C). Almost one-third of the mandibular molars (AL, 37.5\%; AL+Et, 37.0\%) were affected in each alloxan-treated group. No radiolucent change was observed in the alveolar bone around the molars in the control group (Fig. 2A). Thus, the mean alveolar bone resorption scores in the AL $(0.60)$ and $\mathrm{AL}+\mathrm{Et}(0.63)$ groups were significantly higher $(p<0.01)$ than that of the control group (0.00); however, there was no significant difference between the 2 alloxan-treated groups (Fig. 3, Supplementary Table 2: on-line only).

\section{Caries incidence and severity in the soft X-ray exami- nation}

The alloxan-treated groups showed an obviously higher incidence of dental caries (AL, 81.3\%; AL+Et, 79.6\%) than alveolar bone resorption. No radiolucent lesions were observed in any molars of the control group. Thus, the mean caries scores in the AL (1.69) and AL+Et (1.69) groups were also significantly high $(p<0.01)$ compared with the control 


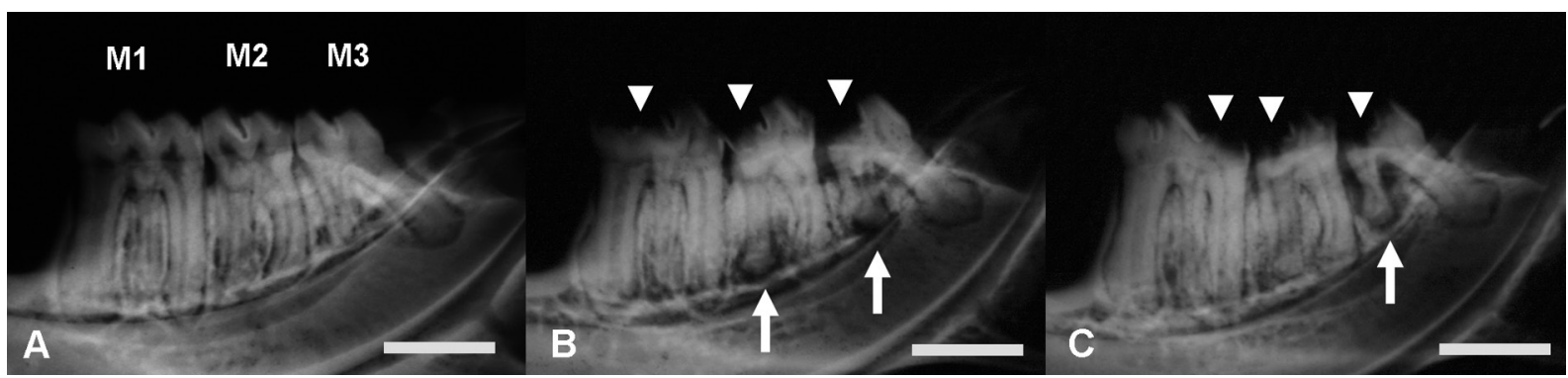

Fig. 2. Soft X-ray images of alveolar bone resorption and dental caries. M1, the first molar; M2, the second molar; and M3, the third molar. A. The mandible of a rat in the control group. Normal alveolar bone and molars. B. The mandible of a rat in the AL group. Dental caries with a radiolucent area (arrowheads) is observed in the dental crown. In the alveolar bone surrounding the carious molars (M2 and M3), a focal radiolucency is detected in the apical portion of the dental root (arrows). C. The mandible of a rat in the AL+Et group. Alveolar bone resorption (arrow) is similarly observed around one (M3) of the carious molars (arrowheads). Scale bar $=2 \mathrm{~mm}$.

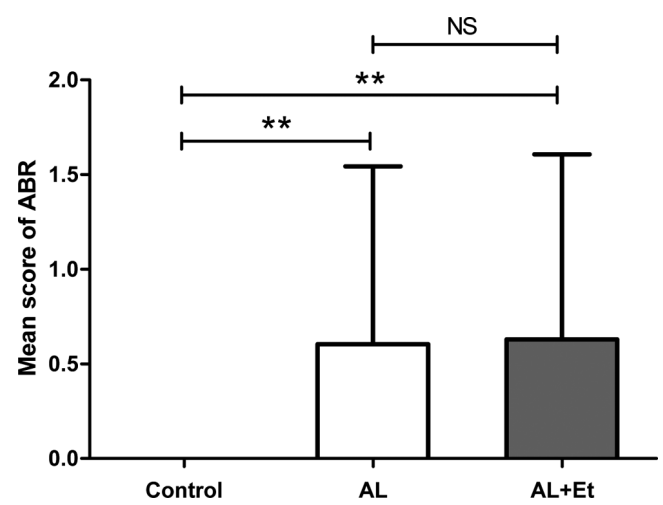

Fig. 3. Mean scores for alveolar bone resorption (ABR) in the mandibular molars of each group. **Significantly different from the control group $(p<0.01)$. NS: no significant difference between the AL and AL+Et groups.

group (0.00). Again, there was no significant difference between the 2 alloxan-treated groups (Fig. 4, Supplementary Table 3: on-line only).

\section{Correlation between alveolar bone resorption scores and caries scores}

The progression of alveolar bone resorption was well correlated with the severity of dental caries in this model (Supplementary Table 4: on-line only). In addition, a high correlation coefficient value was noted between them in both the AL and AL+Et groups (AL: $\mathrm{r}=0.77, p<0.01$; AL+Et: $\mathrm{r}=0.79, p<0.01)$.

\section{Histopathological findings}

Gingivitis of the mandible was observed in $36.7 \%$ of the control group animals, while the incidence was more than double (AL, 81.3\%; AL+Et, 87.0\%) in both alloxan-treated groups. Marginal periodontitis was detected in almost onethird of the mandibular molars (AL, 37.5\%; AL+Et, 35.2\%), corresponding to the incidence of alveolar bone resorption in the soft X-ray examination. This lesion was not observed

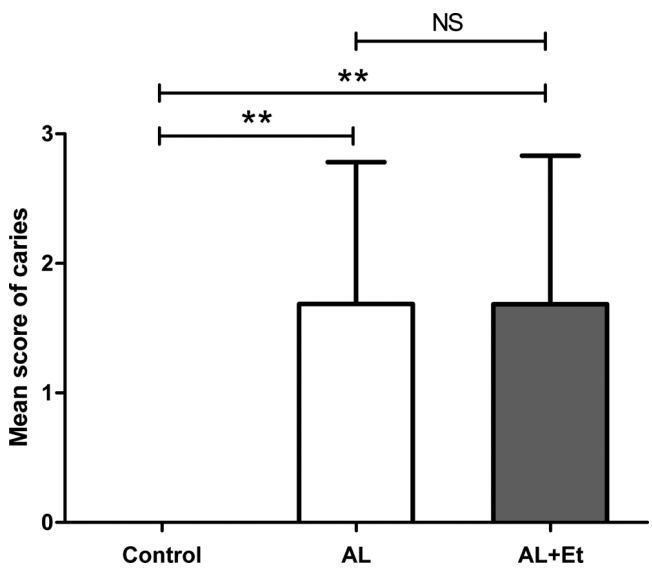

Fig. 4. Mean scores for dental caries in the mandibular molars of each group. **Significantly different from the control group $(p<0.01)$. NS: no significant difference between the AL and AL+Et groups.

in any molar of the control group (Table 2 and Supplementary Table 2: on-line only).

No significant difference in gingivitis and marginal periodontitis was detected between the $\mathrm{AL}$ and $\mathrm{AL}+\mathrm{Et}$ groups, although these lesions were prevalent in both alloxan-treated groups (Table 2). In addition, marginal periodontitis was not detected in any region around noncarious molars regardless of the presence or absence of diabetes. The incidences of gingivitis around noncarious molars were also comparable in all the groups, and there was no significant difference between groups (Fig. 5D-5F, Table 3 and Supplementary Table 5: on-line only).

In both alloxan-treated groups, marginal periodontitis was always accompanied by moderate gingivitis $(++)$ and moderate caries $(++)$ with pulpitis and apical periodontitis. These inflammatory cells in the periodontal tissue (marginal periodontitis) were exclusively continuous with apical purulent inflammation, i.e., apical periodontitis (Fig. 5A-5C, Supplementary Table 5: on-line only). 
Table 2. Incidences of Histopathological Lesions on the Mandible

\begin{tabular}{|c|c|c|c|c|c|c|c|}
\hline Findings & & & $\begin{array}{c}\text { Control } \\
(\mathrm{n}=5)\end{array}$ & & $\begin{array}{c}\mathrm{AL} \\
(\mathrm{n}=8)\end{array}$ & & $\begin{array}{l}A L+E t \\
(n=9)\end{array}$ \\
\hline $\begin{array}{l}\text { No. of } \\
\text { molars }\end{array}$ & & & 30 & & 48 & & 54 \\
\hline \multirow[t]{3}{*}{ Gingivitis } & + & 7 & $(23.3 \%)$ & 10 & $(20.8 \%)$ & 16 & $(29.6 \%)$ \\
\hline & ++ & 4 & (13 & 29 & $(60$. & 31 & $(57$ \\
\hline & Total & 11 & $(36.7)$ & 39 & $(81.3 \%)^{* *}$ & 47 & $(87.0 \%)^{* *}$ \\
\hline Marginal & + & 0 & & 11 & $(22$. & 12 & $(22$ \\
\hline \multirow[t]{2}{*}{ periodontitis } & ++ & 0 & & 7 & (14. & 7 & (13 \\
\hline & Total & 0 & & 18 & $(37.5$ & 19 & $(35.2 \%)^{* *}$ \\
\hline Apica & + & 0 & & 9 & $(18.8 \%)$ & 6 & $(11.1 \%)$ \\
\hline \multirow[t]{2}{*}{ periodontitis } & ++ & 0 & & 14 & $(29.2 \%)$ & 14 & $(25.9 \%)$ \\
\hline & Total & 0 & & 23 & $(47.9 \%)^{* *}$ & 20 & $(37.0 \%)^{* *}$ \\
\hline Carious & + & 1 & $(3.3 \%)$ & 8 & $(16.7 \%)$ & 11 & (20.4\%) \\
\hline \multirow[t]{2}{*}{ lesion } & ++ & 0 & & 32 & $(66.7 \%)$ & 32 & $(59.3 \%)$ \\
\hline & Total & 1 & $(3.3 \%)$ & 40 & $(83.3 \%)^{* *}$ & 43 & $(79.6 \%)^{* *}$ \\
\hline
\end{tabular}

**Significantly different from the control group $(p<0.01)$.

Table 3. Incidences of Histopathological Lesions around Noncarious Molars on the Mandible

\begin{tabular}{|c|c|c|c|c|c|c|c|}
\hline \multicolumn{2}{|l|}{ Findings } & \multicolumn{2}{|r|}{$\begin{array}{l}\text { Control } \\
(\mathrm{n}=5)\end{array}$} & \multicolumn{2}{|r|}{$\begin{array}{c}\text { AL } \\
(n=8)\end{array}$} & \multicolumn{2}{|r|}{$\begin{array}{l}\mathrm{AL}+\mathrm{Et} \\
(\mathrm{n}=9)\end{array}$} \\
\hline \multicolumn{2}{|c|}{$\begin{array}{l}\text { No. of noncarious } \\
\text { molars }\end{array}$} & \multicolumn{2}{|r|}{29} & \multicolumn{2}{|r|}{8} & \multicolumn{2}{|r|}{11} \\
\hline \multirow[t]{3}{*}{ Gingivitis } & + & 6 & $(20.7 \%)$ & 2 & $(25.0 \%)$ & 2 & $(18.2 \%)$ \\
\hline & ++ & 4 & $(13.8 \%)$ & 1 & $(12.5 \%)$ & 2 & $(18.2 \%)$ \\
\hline & Total & 10 & $(34.5 \%)$ & 3 & $(37.5 \%)$ & 4 & $(36.4 \%)$ \\
\hline Marginal & + & 0 & & 0 & & 0 & \\
\hline \multirow[t]{2}{*}{ periodontitis } & ++ & 0 & & 0 & & 0 & \\
\hline & Total & 0 & & 0 & & 0 & \\
\hline \multirow{3}{*}{$\begin{array}{l}\text { Apical } \\
\text { periodontitis }\end{array}$} & + & 0 & & 0 & & 0 & \\
\hline & ++ & 0 & & 0 & & 0 & \\
\hline & Total & 0 & & 0 & & 0 & \\
\hline
\end{tabular}

\section{Discussion}

Periodontal disease (PD) is a human inflammatory disease affecting periodontal tissues such as the gingiva, periodontal ligament and alveolar bone. In the early stage of human PD, dental plaque induces the destruction of gingival fibers leading to the formation of a periodontal pocket. This pocket is then colonized by specific subgingival bacteria, thereby inducing gingivitis and marginal periodontitis. This inflammation progresses apically along the dental root, causing progressive alveolar bone resorption leading to tooth $\operatorname{loss}^{31}$ (Fig. 6A). Several previous animal studies have reported that a PD-derived gingivitis or marginal periodontitis, similar to the human pathological condition, can be spontaneously induced in streptozotocin- or alloxan-induced diabetic rats ${ }^{12,13,32}$. In the present study, the incidence of gingivitis following alloxan treatment notably increased as the diabetic condition worsened. The prevalence of spontaneous gingivitis in our control group correlated well with that of the nondiabetic intact rats in a previous report ${ }^{33}$. In addition, although marginal periodontitis and alveolar bone resorption certainly developed in the AL group, these le-

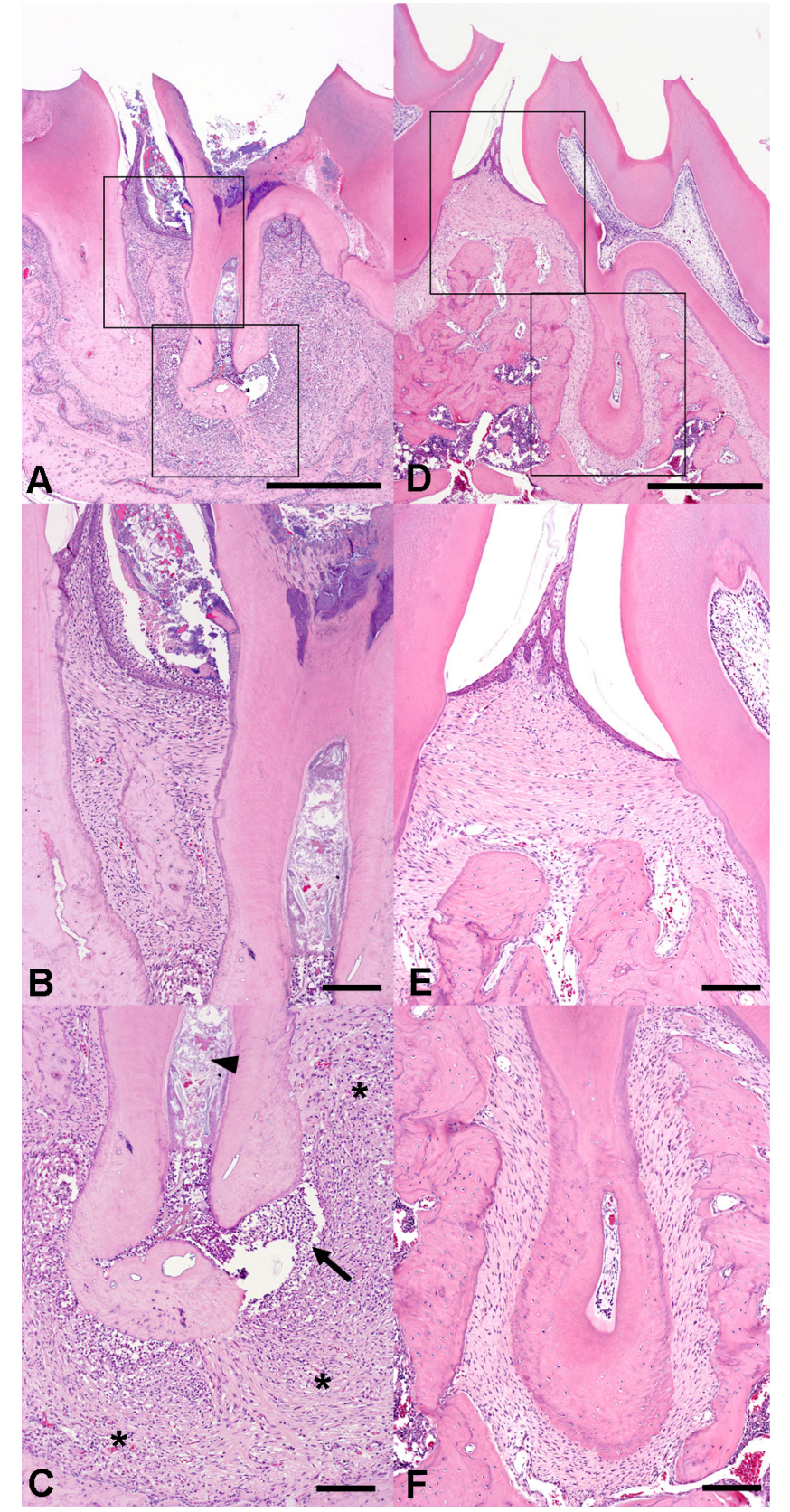

Fig. 5. Histopathologic features of periodontal and carious lesions. The boxes in Fig. 5A correspond to Fig. 5B and 5C. The boxes in Fig. 5D correspond to Fig. 5E and 5F. A-C. Periodontal tissue adjacent to carious molars in an alloxan-induced diabetic rat. A. Severe caries and pulp necrosis; inflammation of dental pulp is continuous with apical inflammation. Scale bar $=500 \mu \mathrm{m}$. B. Moderate gingivitis and marginal periodontitis. Marginal periodontitis is combined with adjacent apical periodontitis (5C). Scale bar $=100 \mu \mathrm{m}$. C. Apical periodontitis; abscess formation (arrow) and extensive inflammatory granulation tissue (asterisks) with alveolar bone resorption in the apical portion of a carious molar root. Suppurative inflammation connects to the necrotic dental pulp (arrowheads) through the apical foramen. Scale bar $=100 \mu \mathrm{m}$. D-F. Periodontal tissue adjacent to a noncarious molar in an alloxaninduced diabetic rat. D. Normal molar and periodontal tissue. Scale bar $=500 \mu \mathrm{m}$. E. Mild gingivitis only. Scale bar $=100$ $\mu \mathrm{m}$. F. Normal apical periodontal tissue. Scale bar $=100 \mu \mathrm{m}$. 

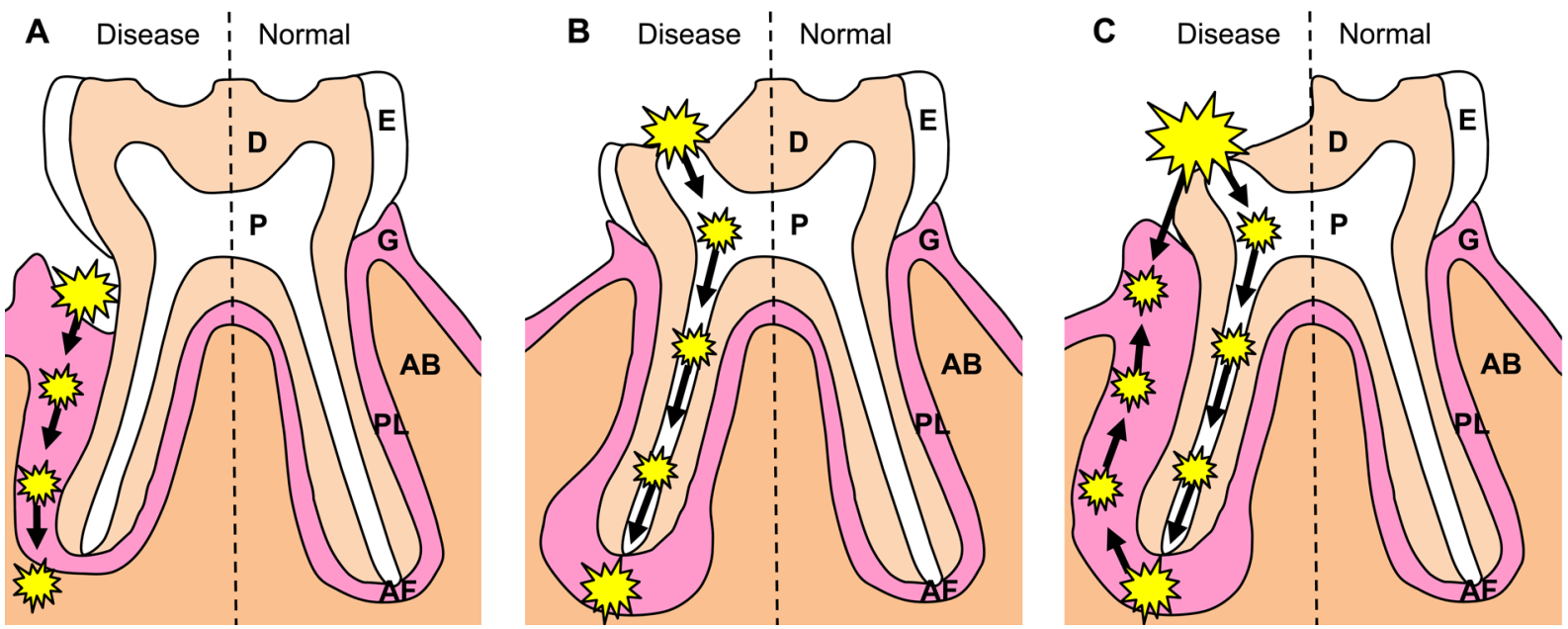

Fig. 6. Diagrammatic representation of the possible pathogenesis of periodontal lesions. A. Periodontal disease. B. Dental caries and caries-derived apical periodontitis. C. Caries-derived periodontal and gingival inflammation in the alloxan-induced diabetic rats. D, dentin; $\mathrm{P}$, pulp; E, enamel; G, gingiva; AB, alveolar bone; PL, periodontal ligament; AF, apical foramen.

sions were not observed in any molar in the control group. While diabetic PD was seemingly reproduced in this diabetic model, a selective COX-2 inhibitor reported to be effective on $\mathrm{PD}^{23-25}$ had no effect on either gingivitis or marginal periodontitis in the AL+Et group. Furthermore, periodontitis was notably nonexistent in the periodontal tissue surrounding the normal molars in the AL group, and gingivitis around the normal molars was scarcely worse than that in the control group. These facts strongly suggest that the inflammatory changes in the periodontal tissue may not be derived from PD in the alloxan-induced diabetic rats and that PD may not actually develop in this model.

Dental caries is a result of demineralization and destruction of hard dental tissue caused by acid. This acid is produced when specific cariogenic bacteria ferment the carbohydrates in the plaque accumulated on the surface of the crown. When dental caries progresses, it penetrates apically through the enamel and dentin of the crown to reach the dental pulp, where inflammation occurs. This pulpitis then expands to the apical aspect of the periodontal tissues via the apical foramen, and apical periodontitis develops ${ }^{34}$ (Fig. 6B). This caries-forming process is consistent with that shown in the alloxan-induced diabetic rats in the current study. Furthermore, $80 \%$ of the alloxan-treated group developed dental caries, though no lesions occurred in any molars of the control group. Thus, it is apparent that hyperglycemia causes dental caries in the alloxan-induced diabetic rats.

The progressive changes of both gingivitis and marginal periodontitis were well correlated with the severity of adjacent dental caries in the alloxan-induced diabetic rats. The finding that marginal periodontitis and apical periodontitis were frequently continuous is in agreement with the findings in diabetic rodents in our previous studies ${ }^{14-17}$. These results suggest that, in this model, apical periodontitis originating from crown caries may progress rostrally to affect the marginal periodontal tissue or gingival tissue along teeth with caries or that the pulpitis of the exposed and decayed crown surface may horizontally progress around gingival tissue (Fig. 6C). In the previous reports, excessive caries-derived inflammation in the upper periodontal tissue might have been confused with PD in the alloxan-induced diabetic rats, despite the fact that the presence of crown caries was identified in this model ${ }^{12,13}$. Our present study, however, clearly indicates that the periodontal inflammation in the alloxan-induced diabetic rats was derived from dental caries.

In conclusion, an alloxan-induced diabetic rat is not a PD model but is a dental caries model. It is probable that, in this model, hyperglycemia may enable crown caries to progress to apical periodontitis, while the associated inflammation may rostrally expand to the surrounding periodontal tissue.

Declaration of Conflicting Interests: The authors have declared no conflicts of interest.

\section{References}

1. Taylor GW, Manz MC, and Borgnakke WS. Diabetes, periodontal diseases, dental caries, and tooth loss: A review of the literature. Compend Contin Educ Dent. 25: 179-184, 186-188, 190; quiz 192. 2004.

2. Mealey BL, Oates TW. American Academy of Periodontology Diabetes mellitus and periodontal diseases. J Periodontol. 77: 1289-1303. 2006. [Medline] [CrossRef]

3. Löe H. Periodontal disease. The sixth complication of diabetes mellitus. Diabetes Care. 16: 329-334. 1993. [Medline]

4. Crawford JM, Taubman MA, and Smith DJ. The natural history of periodontal bone loss in germfree and gnotobiotic rats infected with periodontopathic microorganisms. J Periodontal Res. 13: 316-325. 1978. [Medline] [CrossRef]

5. Samejima Y, Ebisu S, and Okada H. Effect of infection with Eikenella corrodens on the progression of ligature-induced 
periodontitis in rats. J Periodontal Res. 25: 308-315. 1990. [Medline] [CrossRef]

6. Genco CA, Van Dyke T, and Amar S. Animal models for Porphyromonas gingivalis-mediated periodontal disease. Trends Microbiol. 6: 444-449. 1998. [Medline] [CrossRef]

7. Mahamed DA, Marleau A, Alnaeeli M, Singh B, Zhang $\mathrm{X}$, Penninger JM, and Teng YTG. G(-) anaerobes-reactive CD4+ T-cells trigger RANKL-mediated enhanced alveolar bone loss in diabetic NOD mice. Diabetes. 54: 1477-1486. 2005. [Medline] [CrossRef]

8. Watanabe K, Petro BJ, Shlimon AE, and Unterman TG. Effect of periodontitis on insulin resistance and the onset of type 2 diabetes mellitus in Zucker diabetic fatty rats. $\mathrm{J}$ Periodontol. 79: 1208-1216. 2008. [Medline] [CrossRef]

9. Pontes Andersen CC, Buschard K, Flyvbjerg A, Stoltze K, and Holmstrup P. Periodontitis deteriorates metabolic control in type 2 diabetic Goto-Kakizaki rats. J Periodontol. 77: 350-356. 2006. [Medline] [CrossRef]

10. Liu R, Bal HS, Desta T, Krothapalli N, Alyassi M, Luan Q, and Graves DT. Diabetes enhances periodontal bone loss through enhanced resorption and diminished bone formation. J Dent Res. 85: 510-514. 2006. [Medline] [CrossRef]

11. Kador PF, Hamada T, Reinhardt RA, and Blessing K. Effect of an aldose reductase inhibitor on alveolar bone loss associated with periodontitis in diabetic rats. Postgrad Med. 122: 138-144. 2010. [Medline] [CrossRef]

12. Claudino M, Ceolin DS, Alberti S, Cestari TM, Spadella CT, Rubira-Bullen IR, Garlet GP, and de Assis GF. Alloxan-induced diabetes triggers the development of periodontal disease in rats. PLoS ONE. 2: e1320. 2007. [Medline] [CrossRef]

13. Claudino M, Gennaro G, Cestari TM, Spadella CT, Garlet GP, and Assis GF. Spontaneous periodontitis development in diabetic rats involves an unrestricted expression of inflammatory cytokines and tissue destructive factors in the absence of major changes in commensal oral microbiota. Exp Diabetes Res. 2012: 356841. 2012.[Medline] [CrossRef]

14. Kodama Y, Matsuura M, Sano T, Nakahara Y, Ozaki K, Narama I, and Matsuura T. Diabetes enhances dental caries and apical periodontitis in caries-susceptible WBN/KobSlc rats. Comp Med. 61: 53-59. 2011. [Medline]

15. Sano T, Matsuura T, Ozaki K, and Narama I. Dental caries and caries-related periodontitis in type 2 diabetic mice. Vet Pathol. 48: 506-512. 2011. [Medline] [CrossRef]

16. Nakahara Y, Sano T, Kodama Y, Ozaki K, and Matsuura T. Alloxan-induced hyperglycemia causes rapid-onset and progressive dental caries and periodontitis in F344 rats. Histol Histopathol. 27: 1297-1306. 2012. [Medline]

17. Nakahara Y, Sano T, Kodama Y, Ozaki K, and Matsuura T. Glycemic control with insulin prevents progression of dental caries and caries-related periodontitis in diabetic WBN/ KobSlc rats. Toxicol Pathol. 41: 761-769. 2013. [Medline] [CrossRef]

18. Offenbacher S, Odle BM, Gray RC, and Van Dyke TE. Crevicular fluid prostaglandin E levels as a measure of the periodontal disease status of adult and juvenile periodontitis patients. J Periodontal Res. 19: 1-13. 1984. [Medline] [CrossRef]

19. Offenbacher S. Periodontal diseases: pathogenesis. Ann Periodontol. 1: 821-878. 1996. [Medline] [CrossRef]

20. Salvi GE, Beck JD, and Offenbacher S. PGE2, IL-1 beta, and TNF-alpha responses in diabetics as modifiers of periodontal disease expression. Ann Periodontol. 3: 40-50. 1998. [Medline] [CrossRef]

21. Nassar H, Kantarci A, and van Dyke TE. Diabetic periodontitis: a model for activated innate immunity and impaired resolution of inflammation. Periodontol 2000. 43: 233-244. 2007. [Medline] [CrossRef]

22. Paquette DW, and Williams RC. Modulation of host inflammatory mediators as a treatment strategy for periodontal diseases. Periodontol 2000. 24: 239-252. 2000. [Medline] [CrossRef]

23. Bezerra MM, de Lima V, Alencar VB, Vieira IB, Brito GA, Ribeiro RA, and Rocha FA. Selective cyclooxygenase-2 inhibition prevents alveolar bone loss in experimental periodontitis in rats. J Periodontol. 71: 1009-1014. 2000. [Medline] [CrossRef]

24. Lohinai Z, Stachlewitz R, Székely AD, Fehér E, Dézsi L, and Szabó C. Evidence for the expression of cyclooxygenase-2 enzyme in periodontitis. Life Sci. 70: 279-290. 2001. [Medline] [CrossRef]

25. Holzhausen M, Rossa Júnior C, Marcantonio Júnior E, Nassar PO, Spolidório DM, and Spolidório LC. Effect of selective cyclooxygenase- 2 inhibition on the development of ligature-induced periodontitis in rats. J Periodontol. 73: 1030-1036. 2002. [Medline] [CrossRef]

26. Sumi N, Akitsuki S, Fujimoto S, Tawaratani T, Yoshida M, Ishibashi S, Nakazawa M, Uchimoto H, and Nomura A. A three-month oral toxicity study of etodolac in rats followed by one-month recovery test. Oyo Yakuri/Pharmacometrics. 40: 491-513. 1990.

27. Sumi N, Fujimoto S, Tawaratani T, Yoshida M, Ishibashi S, Nakazawa M, Uchimoto H, and Nomura A. A twelvemonth oral toxicity study of etodolac in rats followed by two-month recovery test. Oyo Yakuri/Pharmacometrics. 40: 561-597. 1990.

28. Bacon PA. Safety profile of etodolac in the elderly population. Eur J Rheumatol Inflamm. 14: 19-22. 1994. [Medline]

29. Butler LK. Regulation of blood glucose levels in normal and diabetic rats. In: Tested studies for laboratory teaching (c. A. Goldman, ed.), Proceedings of the 16th Workshop/ Conference of the Association for Biology Laboratory Education (ABLE), 273 pages, 181-202. 1995.

30. Nakhooda AF, Like AA, Chappel CI, Wei CN, and Marliss EB. The spontaneously diabetic Wistar rat (the "BB" rat). Studies prior to and during development of the overt syndrome. Diabetologia. 14: 199-207. 1978. [Medline] [CrossRef]

31. Page RC, and Schroeder HE. Pathogenesis of inflammatory periodontal disease. A summary of current work. Lab Invest. 34: 235-249. 1976. [Medline]

32. Tesseromatis C, Kotsiou A, Parara H, Vairaktaris E, and Tsamouri M. Morphological changes of gingiva in streptozotocin diabetic rats. Int J Dent. 2009: 725628. 2009. [Medline][CrossRef]

33. Goto A, Sonoda J, Seki Y, Taketa Y, Ohta E, Nakano K, Inomata A, Hayakawa K, Aoki T, Tsukidate K, and Hosokawa $\mathrm{S}$. Spontaneous gingivitis related to hair penetration in rats. J Toxicol Pathol. 25: 229-232. 2012. [Medline] [CrossRef]

34. Sunitha V R, Emmadi P, Namasivayam A, Thyegarajan R, and Rajaraman V. The periodontal - endodontic continuum: A review. J Conserv Dent. 11: 54-62. 2008. [Medline] [CrossRef] 